\title{
Rebooting elderly care: The way forward for geriatrics
}

\author{
Rajesh Chauhan* \\ Family Healthcare Centre, India
}

Submission: February 17, 2017; Published: February 22, 2017

*Corresponding author: Rajesh Chauhan, Family Healthcare Centre, Avas Vikas Colony Sikandra, Agra 282007, India, Tel: +919760021192;

E-mail: drrajeshchauhan@gmail.com

\section{Editorial}

All around the world geriatric population is increasing. This is accompanied by its unique problems including issues of senescence and frailty, and at times complicated by multimorbidities [1]. Against the backdrop of increasing numbers of elderly population and their unmet and rising medical requirements with stagnant and dwindling resources at many places around the globe, it's about time that we start to explore creditable newer ideas, concepts and research that are aimed towards helping geriatric population [1]. Having to deal with long term multi-morbidities is as such quite challenging, and the challenge just increases a bit more with the progress of aging. There can be some associated morbidities which may at times get superimposed by a few psychosocial issues as well. Shouldn't our endeavor be to help the elderly achieve graceful aging?

From the perspective of longevity, no one amongst the elderly seems to be looking forward to a life of 1000 years; not yet. To be sure, just try taking views from any youth about their own aging, when they do start getting old. Probably the views would be revealing, and with my experience I dare say that I would expect a prompt response from most of the young and middle aged people when asked this question responding by replying that they would be trying in their own ways to keep healthy till their last breath, and avoid becoming bed-ridden or dependent on anyone when they get old. With the experience gained, for me the aged are no different, and while most of them will never be fearing death, and will have no desire to prolong their lives, they too probably would say that they do not want to fall ill, become bed-ridden, or disabled, and if they had their choice they would never like to become dependent on anyone. Their efforts are therefore directed to stay as fit as possible [2].

In the developing world, it's not that the aged are anyway different. But here, since ages, much reliance was placed on the family structure for support and care, but now that the family structure is disintegrating, the old and infirm are now worried because there is no one to look after them as their health deteriorates [2]. Hence they probably have a desire to remain healthy for as long as possible, for the simple reason of being able to fend for themselves for as long as they can [2]. Fortunately, those who have managed their health well, taken appropriate and timely care of their health problems, and those who are adequately insured medically may not have any such issues or apprehensions.

It should be quite heartening to note that the world is definitely taking steps to alleviate the problems of the old age. Scientists around the world are searching for clues regarding healthy aging [3]. In the elderly population there is permanent decrease of functional capacity, gradual emergence of various diseases leading to the wider multi-morbidity and increased problems in the social sphere, which can develop frailty and social dependency [4]. The authors have emphasized the need of awareness of the problem so that they could understand and cope with this absolutely new reality [4]. Multi-morbidity and the consequent poly-pharmacy are indeed another big challenges globally, that is being appropriately understood and evaluated [5-9].

Therefore it's time that the plight and predicaments of the elderly population should be evaluated and taken into account on an urgent basis. It is no secret that at many places around the globe, the available resources and medical facilities for the elderly population are getting overwhelmed due to increasing demands and unmet needs. Fragmentation of care is also some concern and there are long waiting periods [10]. Some of the aged may be turning despondent and losing hopes due to multi-morbidities, poly-pharmacies, inequities in appropriate and readily available geriatric care, which as such is getting more fragmented with either actual or perceived limitations and inadequacies of geriatricians, and the effect of super-specializations. No doubt, there will always be a requirement of all other specialties, but a time has come where there is a need for Geriatricians to brace up for resolving more, and to refer less [10]. 
For this to happen, firstly of the governments, policy makers, administrators, medical fraternity and world medical bodies, NGOs, community leaders, etc, must all get together and decide about establishing the new norms, scope, up gradation of knowledge, skills and expertise of a geriatrician that become well suited for resolving more and referring less. For this there is a requirement for adding additional knowledge, skills, competence, and expertise. Obviously the medical curriculum during graduation and post graduation has to be suitably upgraded so as to pave way for a new Geriatrician, who is knowledgeable, expert in assessing and dealing with geriatric problems and challenges. With new evidences surfacing regularly, maybe there is a need to refresh our understanding of the geriatric problems regularly. The presentations could be diverse, intertwined and/or mixed, and perhaps not as straight as are met in other age groups. There could be many independent or correlated underlying problems as given below (Figure 1).

\section{Some other factors that need to be considered}

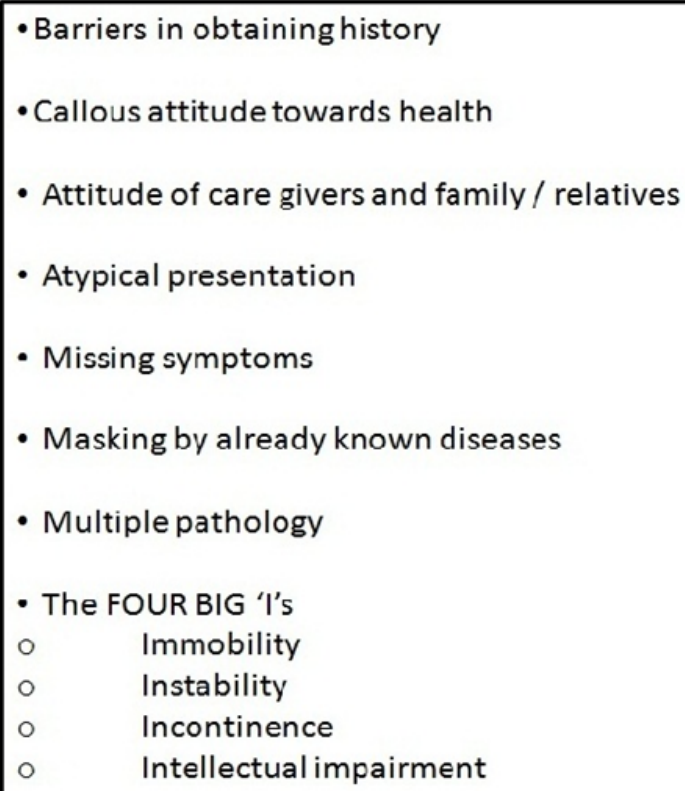

Figure 1: Independent or correlated underlying problems.

Hence, this will require a geriatrician to be more meticulous and alert right from the point when an elderly patient walks in or is brought in for consultation. Observations must be meticulous and thorough, with some structuring that helps in reaching out for a detailed of history and clinical examination. Regular individualized and structured reviews and follow ups will be equally important. Besides senility, there can be many other factors which might play up for which we need to be alert, like underreporting of illness, impairment of homeostasis, vulnerability to various stresses, etc. Some other points that need to be considered are given in (Figure 2).

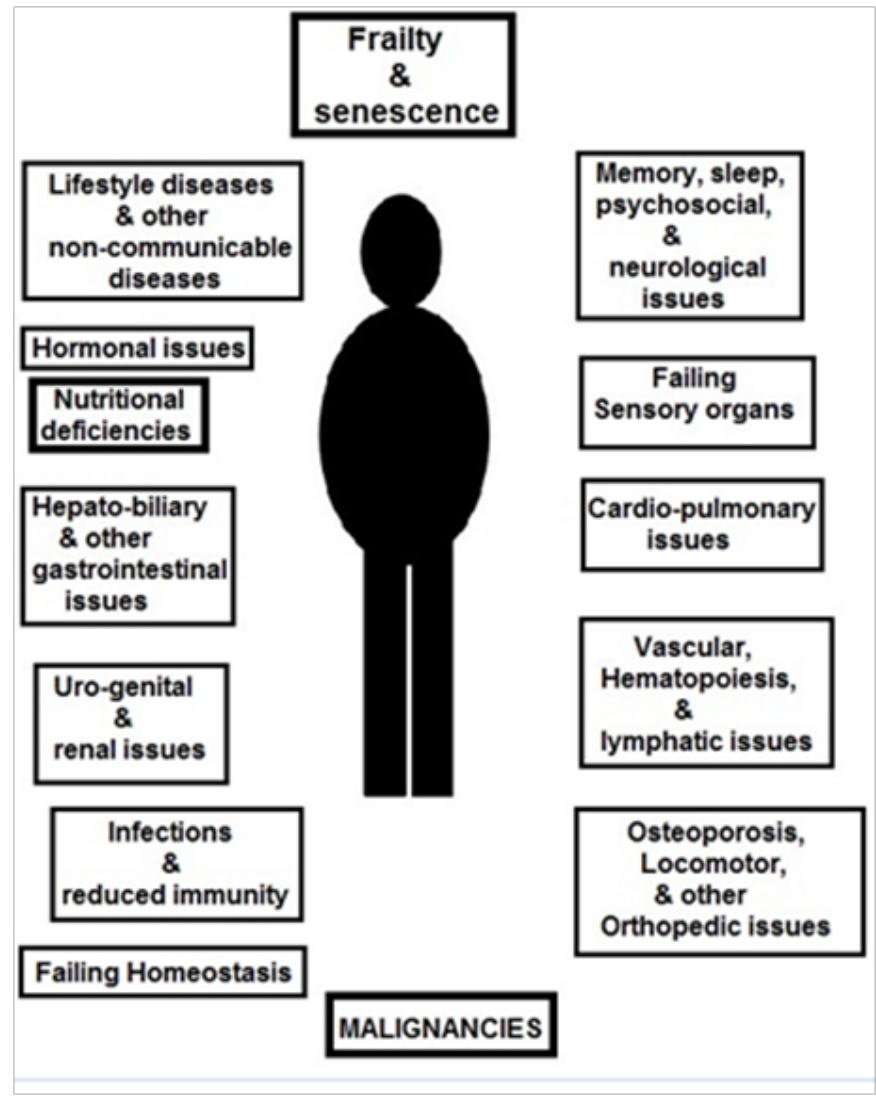

Figure 2: Some other geriatric issues of importance.

As Geriatricians we need to be vigilant and look out for the transition, and also screen and manage risk factors with the ultimate aim of helping them in aging gracefully. There could also be a need for environmental facilitation with all proactive and preventive measures in order to maintain their continued independence, fitness levels, and competence, which might be found getting deteriorated with time. It is perhaps not so difficult to understand that one set of management techniques would not be meeting all the challenges at all times, and therefore the treatment and management will have to be individualized and tailored for better outcomes [11]. Principles of rehabilitation will also have to be suitably modified for individual cases. Assessing \& recording fitness levels should become a routine, and can be undertaken by such simple non-invasive tests like:

i. Katz Index of Independence in Activities of Daily Living

ii. Harvard Step Test

iii. Assessment of V2 MAX

iv. Hand grasp strength assessment by hand dynamometer

v. Mini mental state examination

vi. Pulmonary function test

vii. Vision test

viii. Whispering test with masking 
This is the first issue of this new journal, the Open Access Journal of Gerontology \& Geriatric Medicine (OAJGGM). I wish it becomes another torch bearer the world over in the days to come, for the gerontologists and specialists in geriatric medicine. As an invitee for writing for the very first issue, and a member of the editorial board, it would certainly be my delight I would like to see the journal taking on the challenge of overcoming and managing all accompanying morbidities and poly-pharmacy being addressed from a newer perspective, while sifting through the research that has already been done for the geriatric population and at the same time promoting and gaining from recent researches.

Whatever fears and apprehensions the elderly might have, will possibly be laid to rest by meaningful dialogue about preventive and proactive actions that they would be advised to take, based on not what they hear and see but on actual scientific reasoning and facts. Among other issues involved in the editorial policy, it would be a reasonably good and thoughtful effort if this journal also pitches for giving out vetted comprehensive health bulletins, thereby taking care for the geriatric population's needs as well for accurate and doable information, recommending only indisputable preventive and proactive measures as the need of the day for the elderly and their care givers. Isn't the ultimate aim is to improve the quality of life of the elderly, and provide adequate respite from morbidities?

Finally, in today's world, the direction of future research needs to be carefully steered, and not left to or overtaken by some vested groups to model research. Costly procedures, investigations, medicines, etc, have raised the costs of management. There is surely a need to take a second look at all that is being done or recommended for the elderly patients. Recently there was a study that has revealed that medical errors are the third leading cause of death in the USA [12]. Therefore unnecessary tests, unnecessary procedures, unnecessary medicines, etc, will have to be restrained. Possibly in the free and competitive market, it is all about selling an idea, perhaps, and patients will automatically follow the 'flow'. It is up to the society, the law makers, and the keepers of the society as also the medical and scientific fraternities to decide whether it is $\mathrm{OK}$ to be going with the flow every time. The 'evidence based medicine' also comes to decide the 'evidence' from only the researches that have taken place and have been found published. What about the other 'evidence' that has as yet not been researched in the proper scientific manner, having come about unintentionally, half-heartedly, or maybe accidentally, and for which there are no takers as yet and no one cares? [13].

\section{References}

1. Chauhan R (2016) Editor's Note: Journal of Gerontology and Geriatric Research. J Gerontol Geriatr Res 5: e139.

2. Chauhan R, Singh AK, Kushwah P (2005) Who needs health care? Old people are faced with dilemma as families disintegrate. BMJ 330(7503): 1331-1332.

3. Weber P, Prudius D, Meluzinova H (2015) [Geriatric multimorbidity-one of the key problem of contemporary medicine]. Vnitr Lek 61(12): $1042-1048$.

4. Schäfer I, von Leitner EC, Schön G, Koller D, Hansen H, Kolonko T, et al. (2010) Multimorbidity Patterns in the Elderly: A New Approach of Disease Clustering Identifies Complex Interrelations between Chronic Conditions. PLoS ONE 5(12): e15941.

5. Larsen FB, Pedersen MH, Friis K, Glümer C, Lasgaard M (2017) A Latent Class Analysis of Multimorbidity and the Relationship to SocioDemographic Factors and Health-Related Quality of Life. A National Population-Based Study of 162,283 Danish Adults. PLoS ONE 12(1): e0169426.

6. Walker V, Perret-Guillaume C, Kesse-Guyot E, Agrinier N, Hercberg S, Galan P, et al. (2016) Effect of Multimorbidity on Health Related Quality of Life in Adults Aged 55 Years or Older: Results from the SU.VI. MAX 2 Cohort. PLoS ONE 11(12): e0169282.

7. Ploeg J, Matthew Maich N, Fraser K, Dufour S, McAiney C, Kaasalainen S, et al. (2017) Managing multiple chronic conditions in the community: a Canadian qualitative study of the experiences of older adults, family caregivers and healthcare providers. BMC Geriatr 17(1): 40.

8. Boyd CM, Darer J, Boult C, Fried LP, Boult L, et al. (2005) Clinical Practice Guidelines and Quality of Care for Older Patients with Multiple Comorbid Diseases. JAMA 294(6): 716-724.

9. Onder G, Palmer K, Navickas R, Jurevičienė E, Mammarella F, et al. (2015) Time to face the challenge of multimorbidity. A European perspective from the joint action on chronic diseases and promoting healthy ageing across the life cycle (JA-CHRODIS). Eur J Intern Med. 26(3): 157-159.

10. Rajesh Chauhan (2017) World's attention is also needed for the frail elderly (geriatric) population as well, who may be stuck with multimorbidities and with gaps, insufficiencies, and inequities in care. BMJ 356: j556.

11. Chauhan, Parihar AKS, Chauhan S (2016) Perhaps its Time to Move on to Individually Tailored and Focused Treatment in the Aged Population. J Gerontol Geriatr Res S5: 001.

12. Makary Martin A, Daniel Michael (2016) Medical error-the third leading cause of death in the US BMJ 353 : i2139.

13. Rajesh Chauhan (2017) Kindly don't let accidental discoveries for things like essential hypertension fade away into oblivion. BMJ 351: h3572. 
This work is licensed under Creative Commons Attribution 4.0 Licens

DOI: 10.19080/OAJGGM.2017.01.555554
Your next submission with Juniper Publishers will reach you the below assets

- Quality Editorial service

- Swift Peer Review

- Reprints availability

- E-prints Service

- Manuscript Podcast for convenient understanding

- Global attainment for your research

- Manuscript accessibility in different formats ( Pdf, E-pub, Full Text, Audio)

- Unceasing customer service

Track the below URL for one-step submission https://juniperpublishers.com/online-submission.php 